\title{
Authors' perceptions of electronic publishing: two cross sectional surveys
}

Sara Schroter, Helen Barratt, Jane Smith

\section{BMJ Editorial \\ Office, BMA House, \\ London WC1H 9JR \\ Sara Schroter \\ senior researcher \\ Helen Barratt \\ research assistant \\ Jane Smith \\ deputy editor \\ Corresponding \\ author: S Schroter \\ sschroter@bmj.com}

BMJ 2004;328:1350-3

\begin{abstract}
Objectives To evaluate how acceptable authors find the $B M y$ s s current practice of publishing short versions of research articles in the paper journal and a longer version on the web and to determine authors' attitudes towards publishing only abstracts in the paper journal and publishing unedited versions on bmj.com once papers have been accepted for publication.

Design Two cross sectional surveys.

Setting General medical journal.

Participants Survey 1: corresponding authors of a consecutive sample of published $B M J$ research articles that had undergone the ELPS (electronic long, paper short) process. Survey 2: corresponding authors of consecutive research articles submitted to $B M J$.

Results Response rates were 90\% (104/115) in survey 1 and $75 \%(213 / 283)$ in survey 2. ELPS is largely acceptable to $B M J$ authors, but there is some concern that electronic information is not permanent and uncertainty about how versions are referenced. While authors who had experienced ELPS reported some problems with editors shortening papers, most were able to rectify these. Overall, $70 \%$ thought that the BMJ should continue to use ELPS; $49 \%$ thought that publishing just the abstract in the printed journal with the full version only on bmj.com was unacceptable; and $23 \%$ thought it unacceptable to post unedited versions on bmj.com once a paper had been accepted for publication.

Conclusions It is acceptable to authors to publish short versions of research articles in the printed version of a general medical journal with longer versions on the website. Authors dislike the idea of publishing only abstracts in the printed journal but are in favour of posting accepted articles on the website ahead of the printed version.
\end{abstract}

\section{Introduction}

Widespread use of the internet has led to innovative ideas for presenting results of scientific research. Electronic publishing is not limited by restrictions on space, like in printed journals, so more material can be published and in different formats. Biomedical journals are making increasing use of this medium, and some are experimenting with different approaches. However, little is known about what authors and readers think of these innovations. Publishers have a responsibility to readers and authors to produce a journal that is readable and allows readers to critically appraise the studies published.

Almost all BMJ research articles are now published as abridged versions in the printed journal with a longer version available on bmj.com. ${ }^{1-3}$ The thinking behind ELPS (electronic long, paper short) is that general readers want short and well written papers that provide the gist of the study without going into great detail, while other readers may want a more comprehensive account of how a study was carried out. Editors prepare the shorter version, and authors approve the proofs of both versions before publication. When readers go to bmj.com they can access both versions.

Making changes to the traditional format of medical publishing initially stimulated both positive and negative responses from $B M J$ readers. ${ }^{4}$ Editors hoped their readers and authors would grow to like ELPS once they became accustomed to it, ${ }^{4}$ but until now there has been no formal evaluation of its acceptability. We carried out two cross sectional surveys to evaluate whether ELPS is acceptable to authors and to investigate authors' attitudes towards two different approaches to electronic publishing.

\section{Methods}

We surveyed two samples of authors. Survey 1 included authors who had experienced ELPS, and survey 2 included authors submitting papers to the $B M J$, who may not have previously published in the journal.

In survey 1 we sent a letter explaining the ELPS process and a questionnaire (see appendix 1 on bmj.com) to corresponding authors of research papers published in July 2001 to June 2002 that had undergone the ELPS process. Authors were asked which aspects of ELPS they liked and disliked, about problems encountered with the process, and how readable they thought the short paper was compared with the long.

In survey 2 we sent a letter explaining the ELPS process and a questionnaire (see appendix 2 on bmj.com) to the corresponding author of each research paper submitted to $B M J$ over five weeks in 2002. Authors were asked whether they knew about ELPS before the survey and what they liked and disliked about the idea of ELPS.

We also asked all participants for their opinions of two further approaches to publishing research articles: publishing only abstracts in the paper version and full articles on bmj.com, and publishing unedited versions of papers on bmj.com as soon as they have been accepted for publication.

We used standard methods for optimising survey response rates, such as the use of personalised letters, return envelopes, and reminders. ${ }^{56}$ Non-responders were sent reminders three and six weeks after the original mailing.

\section{Results}

\section{Participants}

We excluded five of the 120 questionnaires sent out in survey 1 , as the contact address was incorrect (returned

The questionnaires sent to authors can be found on bmj.com. This article was posted on bmj.com on 19 May 2004: http://bmj.com/cgi/doi 10.1136/bmj.38117.624259.55 


\begin{tabular}{|c|c|c|c|}
\hline & $\begin{array}{c}\text { Survey } 1 \\
(n=104)\end{array}$ & $\begin{array}{c}\text { Survey } 2 \\
(\mathrm{n}=213)\end{array}$ & $\begin{array}{l}\text { Both surveys } \\
(\mathrm{n}=317)\end{array}$ \\
\hline \multicolumn{4}{|l|}{ What do you like about the concept of ELPS?† } \\
\hline Idea of making research papers more accessible/readable & $85(82)$ & $168(79)$ & $253(80)$ \\
\hline Opportunity of writing longer version for web and not being restricted to just short version & $79(76)$ & $122(57)$ & $201(63)$ \\
\hline Editors prepare shorter version of paper & $41(39)$ & $94(44)$ & $135(43)$ \\
\hline Thought it might speed up publication process & $17(16)$ & $60(28)$ & $77(24)$ \\
\hline \multicolumn{4}{|l|}{ What don't you like about the concept of ELPS? $\dagger$} \\
\hline Don't like anything about it & $7(7)$ & $10(5)$ & $17(5)$ \\
\hline Don't believe readers want shorter papers & $9(9)$ & $16(8)$ & $25(8)$ \\
\hline Confusing to have two versions of same paper & $38(37)$ & $80(38)$ & $118(37)$ \\
\hline Don't like editors preparing shorter version of paper & $31(30)$ & $47(22)$ & $78(25)$ \\
\hline Don't/wouldn't feel comfortable having my name on the shorter version of paper prepared by editor & $12(12)$ & $38(18)$ & $50(16)$ \\
\hline Dislike possibility of information on web being transient & $42(40)$ & $52(24)$ & $94(30)$ \\
\hline Printed information is permanent whereas electronic files might not be & $38(37)$ & $59(28)$ & $97(31)$ \\
\hline \multicolumn{4}{|c|}{$\begin{array}{l}\text { In general do you think the short versions of papers in the printed } B M J \text { are more readable (for general readers) than the long versions on our website } \\
\text { (bmj.com)? }\end{array}$} \\
\hline More readable & $39(38)$ & $88(41)$ & $127(40)$ \\
\hline About the same & $33(32)$ & $32(15)$ & $65(21)$ \\
\hline Less readable & $10(10)$ & $3(1)$ & $13(4)$ \\
\hline Never read both versions of same article & $19(18)$ & $81(38)$ & $100(32)$ \\
\hline \multicolumn{4}{|c|}{ Do you think the short version of your paper in the printed $B M J$ is more or less readable (for general readers) than the long version? } \\
\hline More readable & $32(31)$ & - & - \\
\hline About the same & $54(52)$ & - & - \\
\hline Less readable & $14(14)$ & - & - \\
\hline Never read both versions of article & $3(3)$ & - & - \\
\hline \multicolumn{4}{|c|}{ Will the ELPS process (knowing that we will shorten your paper) stop you from submitting papers to the $B M J$ in the future? } \\
\hline Yes & $4(4)$ & $4(2)$ & $8(3)$ \\
\hline No & $88(85)$ & $179(84)$ & $267(84)$ \\
\hline Don’t know & $10(10)$ & $24(11)$ & $34(11)$ \\
\hline I am unlikely to submit papers to $B M J$ for other reasons & $0(0)$ & $3(1)$ & $3(1)$ \\
\hline \multicolumn{4}{|l|}{ Should $B M J$ continue to use ELPS? } \\
\hline Yes & $72(69)$ & $151(71)$ & $223(70)$ \\
\hline No & $10(10)$ & $13(6)$ & $23(7)$ \\
\hline Don't know & $19(18)$ & $45(21)$ & $64(20)$ \\
\hline \multicolumn{4}{|c|}{$\begin{array}{l}\text { As an author, how acceptable would it be for us to publish only the abstract of papers in the paper journal and continue to put the full long version on our } \\
\text { website? }\end{array}$} \\
\hline Very acceptable & $3(3)$ & $15(7)$ & $18(6)$ \\
\hline Acceptable & $8(8)$ & $35(16)$ & $43(14)$ \\
\hline Acceptable, but would prefer not & $27(26)$ & $67(32)$ & $94(30)$ \\
\hline Not at all acceptable & $65(63)$ & $91(43)$ & $156(49)$ \\
\hline \multicolumn{4}{|c|}{$\begin{array}{l}\text { As an author, how acceptable would it be for us to post unedited versions (not technically edited to remove inconsistencies and ambiguities) of the full (Iong) } \\
\text { paper on our website as soon as we accept it for publication? }\end{array}$} \\
\hline Very acceptable & $22(21)$ & $29(14)$ & $51(16)$ \\
\hline Acceptable & $24(23)$ & $76(36)$ & $100(32)$ \\
\hline Acceptable, but would prefer not & $32(31)$ & $54(25)$ & $86(27)$ \\
\hline Not at all acceptable & $23(22)$ & $50(24)$ & $73(23)$ \\
\hline \multicolumn{4}{|l|}{ Would posting unedited versions make you more or less likely to submit papers to $B M J$ ? } \\
\hline More likely & $19(18)$ & $33(16)$ & $52(16)$ \\
\hline Less likely & $15(14)$ & $26(12)$ & $41(13)$ \\
\hline No influence & $67(64)$ & $149(70)$ & $216(68)$ \\
\hline
\end{tabular}

Percentages do not add up to 100 because of missing data.

†Respondents were asked to tick all that apply.

by post office). Of the 115 eligible authors, 104 (90\%) responded.

We excluded 14 of the 297 questionnaires sent out in survey 2 as the contact address was incorrect. Of the 283 eligible authors, 213 (75\%) responded. Of these, $60 \%(128 / 213)$ reported that they were aware of ELPS before the survey and 13\% (27/213) had previously been an author on a paper that had undergone ELPS.

As responses were largely similar in the two surveys we combined the results for reporting purposes (except when the groups differed) but have also presented the results for each survey separately in the table.
What do authors like and dislike about the concept of ELPS?

Of the 317 respondents, $80 \%$ (253/317) liked the idea of making papers more accessible and not being restricted to just a short version; 43\% (135/317) liked the fact that editors prepare the shorter version of the paper on their behalf; and 24\% (77/317) thought ELPS may speed up the publication process $(16 \%$ in survey 1 and $28 \%$ in survey 2 ; table).

Only 5\% (17/317) of authors didn't like anything at all about ELPS, and 8\% (25/317) didn't believe that readers wanted shorter papers. Both groups reported concerns about the possibility of information on the 
internet being transient $(42 / 104(40 \%)$, in survey 1 ; $52 / 213(24 \%)$ in survey 2$)$ and over a third (118/317, $37 \%$ ) found it confusing to have two versions of the same paper. Most felt comfortable with having their name on the shorter version of the paper prepared by the editor.

Additional reasons for not liking ELPS largely focused on problems with editors shortening papers (inappropriate selection of material, important omissions, disjointed narrative, "dumbing down" of science); the unsuitability of some study designs for short versions (for example, systematic reviews and qualitative research); additional proof reading; and problems of accessing the long version for those with no internet access.

\section{Readability}

Over a third of authors thought that the short versions of papers in the printed $B M J$ are more readable (for general readers) than the long versions on bmj.com, and only a few $(4 \%, 13 / 317)$ reported they are less readable (table). Of the authors in survey 1, 14\% (14/104) thought that the short version of their own paper was less readable than the long version.

\section{Concern over the editor preparing the short version}

From the respondents in survey 1, half (53/104) reported they were initially concerned by the idea of an editor preparing the shorter version of their paper, but $30 \%(16 / 53)$ of these later reported that they liked ELPS more having experienced it. About 46\% $(48 / 104)$ reported that there were aspects of the shorter version of their paper prepared by an editor that they were not happy with. Problems largely focused on editors changing the meaning and interpretation, as well as important omissions potentially affecting the comprehension and context of the study. However, $65 \%(31 / 48)$ said they had the opportunity to amend this.

\section{Satisfaction with ELPS}

Overall, $70 \%$ (95\% confidence interval $64 \%$ to $76 \%$ ) of authors $(223 / 317)$ thought that the BMJ should continue with ELPS. Only 3\% (8/317) said that ELPS would stop them from submitting to $B M J$ in the future (table).

\section{Acceptability of two further approaches to electronic publishing}

Nearly half $(49 \%, 41 \%$ to $57 \% ; 156 / 317)$ reported that it would be "not at all acceptable" to publish only the abstract of papers in the paper journal and put the full long version on bmj.com (table). Also, 23\% (13\% to $33 \%$; 73/317) reported that posting an unedited version of the full paper on the website on acceptance was "not at all acceptable" but 48\% (40\% to 56\%; $151 / 317)$ reported it would be acceptable. Around $68 \%(216 / 317)$ thought it would not influence their likelihood of submitting papers to $B M J$, and $16 \%$ (52/317) thought it would make them more likely to submit. While some were concerned by the potential quality of unedited papers, many emphasised the need for rapid dissemination of important clinical findings.

\section{What is already known on this topic}

Widespread use of the internet has led to innovative ideas for presenting scientific research

Little is known about what authors and readers think of these innovations

\section{What this study adds}

Authors think it is acceptable to publish short versions of research articles in the printed version of a general medical journal with longer versions on the website

Authors dislike the idea of publishing only abstracts in the printed journal but are in favour of posting accepted articles on the website ahead of the printed version

\section{Discussion}

Publishing condensed versions of research articles in the printed version of a general medical journal and the longer versions on the web is largely acceptable to authors who have experienced the process and to authors who may not be familiar with it. Most authors thought that $B M J$ should continue to use ELPS, that the short versions of papers are more readable than the long, and that the process will not stop them submitting to the journal. Some were concerned over the possibility of information on the internet being transient, and editors may need to do more to ensure that their publications will be permanent and to reassure authors of that.

Most authors in both surveys thought that publishing only the abstract of articles in the paper journal with the full long version on bmj.com was clearly unacceptable. Posting unedited versions of the full paper on bmj.com as soon as it is accepted for publication was considered broadly acceptable and would not prevent most authors from submitting to the journal. The $B M J$ has now introduced Online First (whereby original research is posted on bmj.com before it appears in print). The decision to post edited versions on Online First was influenced by the finding that half the authors in this study thought it would be unacceptable to publish unedited versions.

This study is limited in that it was conducted with authors from only one medical journal and asked questions specific to this journal's practice. However, the $B M J$ is a general medical journal with authors from all disciplines of health care, and we included both submitting and published authors, so authors in this study are likely to be representative of the larger community of biomedical authors.

With so many opportunities in electronic publishing, it is important to involve readers and authors in the evaluation of new practices. The high response rates to both surveys reflect authors' willingness to contribute to these evaluations. We hope to encourage other journals to consider adopting different approaches of electronic publishing and to evaluate the acceptability to users. 
We thank all the authors for taking part; and Marcus Müllner, Trish Groves, Fred Kavelier, and Julia Thompson for assisting in the refinement of the questionnaires.

Contributors: JS initiated the study. SS and JS designed the study. SS developed the questionnaires with assistance from the $B M J$ editorial team. SS and HB conducted the surveys and managed the data collection. SS analysed the data. SS wrote the paper, and all authors helped revise it. SS is guarantor.

Funding: BMJ Publishing Group's research budget.

Competing interests: SS is research manager for the BMJ Publishing Group, and $\mathrm{HB}$ was working at the $B M J$ as a research assistant while conducting this research. JS is the managing editor of the $B M J$. Because members of $B M J$ staff were involved in the conduct of this research and writing the paper, assessment and peer review have been carried out entirely by external advisors. No member of $B M J$ staff has been involved in making the decision on the paper.
Ethical approval: Not required.

1 Delamothe T, Müllner M, Smith R. Pleasing both authors and reader BMJ 1999;318:888-9

2 Müllner M, Groves T. Making research papers in the BMJ more accessible. BMJ 2002;325:456.

3 Müllner M. Publishing short articles in the print journal and full articles on the web? The $B M J$ is doing it with most research papers Eur J Sci Edit 2003;29:6-9.

4 Electronic responses. Pleasing both authors and readers. BMJ 1999 www.bmj.com/cgi/content/full/318/7188/777\#responses (accessed 21 Nov 2003).

5 Dillman DA. Mail and telephone surveys: the total design method. New York: Wiley, 1978.

6 Edwards P, Roberts I, Clarke M, DiGuiseppi C, Pratap S, Wentz R. Increasing response rates to postal questionnaires: systematic review. BMJ 2002;324:1183.

(Accepted 28 March 2004)

doi $10.1136 /$ bmj.38117.624259.55

\section{DRUG POINTS}

\section{Slipped capital femoral epiphyses associated with the withdrawal of a gonadotrophin releasing hormone}

Eugène van Puijenbroek, Emil Verhoef, Linda de Graaf

Leuprorelin, buserelin, and triptorelin belong to the group of gonadotrophin releasing hormone $(\mathrm{GnRH})$ analogues. Kempers and Noordam previously reported an association between slipped capital femoral epiphysis during treatment with buserelin and triptorelin, or shortly after discontinuation of these drugs. ${ }^{1}$

The Netherlands Pharmacovigilance Centre Lareb received a report concerning an 11 year old girl who had been using leuprorelin $3.75 \mathrm{mg}$ once monthly over four years, for precocious puberty. Seven months after the last injection she experienced pain in her right leg. An ultrasound showed a slight excess of synovial fluid in the hip. The pain increased, and in addition the patient complained about pain in her left hip. Two months later an $\mathrm{x}$ ray film showed bilateral slipped capital femoral epiphyses of both hips. The patient recovered fully after treatment with a dynamic hip screw. The initial symptoms coincided with the increase in growth velocity shortly after treatment with leuprorelin was stopped (figure).

Slipped capital femoral epiphyses occur mainly in boys in late childhood or adolescence and are associated with delayed skeletal maturation, overweight, high growth velocity, and tall stature. ${ }^{2}$ The incidence is reported to vary between $0.71 / 100000$ and $61 / 100000 .{ }^{1}$ None of the patients described in literature met the typical risk factors, and neither did our patient. Four out of five events of slipped capital femoral epiphyses associated with GnRH agonist reported in the literature, as well as in our patient, occurred shortly after the drug had been discontinued. The assumption had been that during treatment with a GnRH agonist low oestrogen concentrations decrease epiphyseal activity and weaken the epiphyseal plate. ${ }^{1}$ The increase in growth velocity after stopping GnRH agonist, subsequently results in a reduction of the shearing force needed for the displacement of the epiphysis. ${ }^{1}$ A similar mechanism may be involved in children treated with growth hormone, who were more likely to develop slipped capital femoral

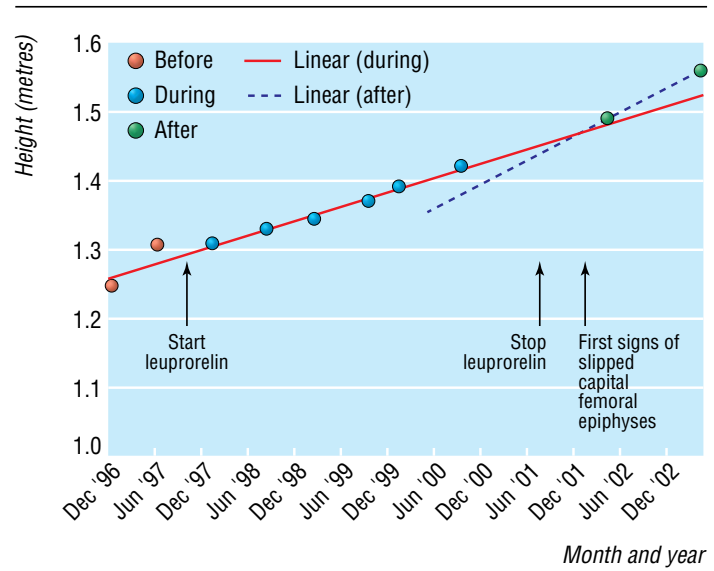

Patient's growth curve before, during, and after the use of leuprorelin; linear trend lines during and after use

epiphyses than children with idiopathic short stature who were not treated. ${ }^{3}$ We suggest that cessation of $\mathrm{GnRH}$ agonists be added to the list of known risk factors for slipped capital femoral epiphysis.

Contributors: EvP wrote the paper, searched the literature, and is the guarantor. $\mathrm{EV}$ is the general practitioner of the patient involved, collected data, and corrected the draft article. LdeG drafted the article, searched the literature, and corrected the draft.

Competing interests: None declared.

1 Kempers MJ, Noordam C, Rouwe CW, Otten BJ. Can GnRH-agonist treatment cause slipped capital femoral epiphysis? J Pediatr Endocrinol Metab 2001;14:729-34

2 Skinner SR. Slipped upper femoral epiphysis. In Rudolph AM, Hoffman JIE, Rudolph CD, eds. Rudolph's pediatrics. Stamford, CT: Appleton and Lange, 2003:2145-6.

3 Blethen SL, Rundle AC. Slipped capital femoral epiphysis in children treated with growth hormone. A summary of the national

cooperative growth study experience. Horm Res 1996;46:113-6. 